\title{
Discovering Sentiments and Latent Themes in the Views of Faculty Members towards the Shift from Conventional to Online Teaching Using VADER and Latent Dirichlet Allocation
}

\author{
Niel Francis B. Casillano
}

\begin{abstract}
This research primarily aimed at determining the frequently occurring words, the sentiment and the underlying latent themes in the responses of faculty members towards the shift from conventional to online teaching using data mining techniques. Orange data mining software was utilized to preprocess and analyze the data. VADER sentiment analysis and Latent Dirichlet Allocation Topic Modelling were used to generate the overall sentiment and the themes of the teachers' responses. Results revealed that the most frequently occurring words in the responses of teachers were blended, online, students, teaching, teachers, learning, difficult, challenging, internet, and connectivity. Twenty-three (23) out of $37(62 \%)$ responses were determined to have negative polarity making the general sentiment of faculty members towards the shift to online learning negative. The following themes were generated after the application of Latent Dirichlet Allocation Topic Modeling technique: unexpected shift from conventional to blended teaching, Mental and Physical Health Issues Related to the Implementation of Blended Learning, Online tools used in the conduct of Online Classes, Difficulties and Challenges in the Conduct of Blended/Online Learning, Slow Internet Connectivity as a Major Impediment in the Conduct of Online Teaching.
\end{abstract}

Index Terms - Latent dirichlet allocation, topic modelling, sentiment analysis, pandemic, teacher, COVID-19.

\section{INTRODUCTION}

For several industries, including education, the COVID-19 Pandemic is a fundamental, adaptable, and revolutionary challenge. Many countries are putting in place policies that limit the amount of people who congregate in public spaces. The usual operation of schools and universities has been affected as a result of such initiatives. Because the duration of such measures has been extensive - and is likely to continue for some time a large number of persons have been fully vaccinated - leaders of public and private educational institutions have implemented alternative methods for students and teachers to continue with their lessons while physically attending school is not possible [1]. This has caused many educators to suddenly teach their lessons online, which entails opportunities to reshape education, teacher education and educational institutions in general [2], but it also entails a very big challenge to many educators who are struggling with very complex online technology. The employment of blended learning has posed different

Manuscript received June 15, 2021; revised September 16, 2021.

The author is with the Information Technology Department, Eastern Samar State University, Borongan City, Philippines (e-mail: nfcasillano@gmail.com). challenges, difficulties and risks to both the teachers and students, especially in the higher education institutions (HEIs) [3].

In March 2020, the Commission on Higher Education gave HEI's academic freedom and the option to implement available distance learning, e-learning, and other alternative modes of delivery to students [4]. In the case of State Universities and Colleges in Region VIII, the Commission on Higher Education has suggested to establish a Flexible learning management consortium and conduct a series of trainings to equip faculty member with the necessary skills needed to conduct flexible learning. Eastern Samar State University however has been struggling in conducting online teaching even before the pandemic [5].

Presently, the many universities are using different modalities to deliver instruction but because of the limited movement allowed by Local Government units (LGU), teachers are left with using online tools to conduct real-time classes and to promptly respond to students' queries. With this on-going practice, it was also observed that many are not familiar with new videoconferencing technology needed to conduct face-to-face online learning. Emotional distress, burnout, and health issues are becoming prevalent. Administrators were not always aware of such issues, which limited their capacity to assist because each problem necessitated a unique response [6]. The teachers' well-being, the challenges they are facing and their quality of life generally must continuous be given attention. Teachers must also be supported as they adjust to the impact of the COVID-19 pandemic [7]. Due to a lack of feedback from school administration, particularly during pandemics, struggling instructors are forced to work without a crucial tool that could improve their performance, causing the situation to rapidly deteriorate [8]. This observation has prompted the researchers to investigate and identify the sentiments of teachers towards the shift from conventional to online teaching. In this study the researchers extracted and determined the views and sentiments of teachers towards online learning using Valence Aware Dictionary for sEntiment Reasoning (VADER) model and a topic modeling technique called Latent Dirichlet Allocation Algorithm.

\section{OBJECTIVES}

This study focused on exploring responses that were collated from the Faculty Members of Eastern Samar State University. The collection of responses was preprocessed and the resulting data served as inputs to a machine learning 
tool to produce sentiment analysis and topic modeling results.

Specifically, this study aims to achieve the following:

1) Determine the frequently occurring words in the collection of documents through a word cloud.

2) Identify the Over-all sentiment of the collection of documents using the Valence Aware Dictionary for sEntiment Reasoning (VADER) model and a Heat Map

3) Identify the hidden and prevalent themes in the different responses as produced by employing Latent Dirichlet Allocation Algorithm Topic Modelling technique

\section{RELATED STUDIES}

\section{A. Shift from Conventional to Online Teaching}

Since October 2020, the COVID-19 pandemic has infected more than 36 million people and more than a million has already perished. In the Philippines, this translates into almost 325,000 infected and 6,000 deaths [9], [10]. This has left unprecedented impacts to the education system of various higher education institutions [11]. To mitigate the disruption caused by the pandemic to the educational system of the Philippines and to cater the needs of more than 3.5 million tertiary level students enrolled in more than 2400 Higher Education institutions, a wide-array of flexible learning modalities and proactive policies has been implemented to continue the learning despite their closure. Some of the universities that implemented online synchronous and asynchronous learning were Eastern Samar State University (ESSU), De La Salle University, University of Santo Tomas, Ateneo de Manila University and the University of the Philippines [10]. The Commission on Higher Education also made it sure that the implementation of alternative learning modalities will serve not only those with internet connectivity, the CHEd chairman explained the idea of flexible learning as a more encompassing modality than pure online learning. He mentioned that flexible learning does not require connectivity instead in focuses on the implementation of programs and courses that will address the students' specific needs in terms of terms of his ability complete the learning material on time, his internet connectivity and his location [12].

The Philippines is one of the countries with the slowest internet connectivity in Asia [13]. This leads to the inability of the students to access their self-learning modules remotely and has to travel to areas where there is a strong internet connectivity risking and exposing them to the virus. The teachers' competence in terms of providing education from the conventional classroom to the realm of virtual reality must be reinforced. Each institution must study and determine the best learning modality that the school can adopt to make sure that each student gets quality education [14].

\section{B. Sentiment Analysis}

With the massive amount of information being generated on various online platforms such as social media sites, online review sites, blogs, and opinion sharing platforms, sentiment analysis through text mining and natural language processing
(NLP) is now gaining more attention [15]. Through sentiment analysis, online documents, corpus, comments, blogs and reviews can easily be analyzed and categorized into ins compounded sentiment either positive, negative or neutral [16]. Sentiment analysis involves a set of complex processes. Steps such as sentiment classification, subjective analysis, opinion holder extraction and aspect-based extraction must be done to determine the over-all sentiment of a particular document. Each document undergoes subjective analysis where each are tagged either subjective or objective and discards those that are tagged as objective for, they are not of use during sentiment analysis. Each sentence within the document is examined carefully to determine its polarity which can either be negative, positive or neutral [16].

\section{Methodology}

\section{A. Research Design}

This study utilized an Exploratory Sequential Mixed Methods where the initial phase starts with data collection using qualitative information and analysis, then followed by quantitative data generation and analysis with a concluding stage of data analysis combining the two results [17]. To support the intention of the research, this study used Relational analysis specifically Sentiment analysis [18]. Sentiment Analysis starts with data or text classification present in the text corpus. This research underwent four (4) steps focusing on qualitative data collection through the responses from faculty members, qualitative data processing, and themes development.

\section{B. Text Preprocessing and Cleaning}

An open-ended question was sent to all colleges of Eastern Samar State University through Google Forms. The first part of the form contained a data privacy notice to comply with the Data Privacy Act of 2012. A total of thirty-seven (37) exhaustive responses were collated from the faculty members. Each response remained anonymous and were named as part1, part2, part3 and so on. The responses were then downloaded in a excel sheet and was loaded into Orange Data Mining Software. All responses underwent text preprocessing and cleaning. In the preprocessing stage, information extraction from the documents is performed to identify keywords and relationships within the text this is also known as pattern matching. This technology is very advantageous when dealing with large volumes of text. The preprocessing and cleaning methods performed in this research are:

Stopwords Removal: Natural language has a division called stop words. The reason for removing stop-words from a text is that they make it appear heavier and less essential to analysts. The dimensionality of term space is reduced when stop words are removed. Articles, prepositions, and pronouns are the most common words in text documents, yet they do not convey the meaning of the writings [19].

Stemming: This method is used to determine a word's root/stem. The words connect, connected, connecting, and connections, for example, can all be traced back to the word "connect" [20]. The goal of this strategy is to eliminate 
multiple suffixes, minimize the number of words, ensure that stems are precisely matched, and save time and memory space [19].

Term Frequency-Inverse Document Frequency: The Term Frequency-Inverse Document Frequency (TF-IDF) is a numerical statistic that shows how essential a word is to a collection of documents. Information retrieval and text mining frequently use the TF-IDF as a weighting factor. The value of TF-IDF rises in proportion to the number of times a word appears in the document, but the frequency of the word in the corpus balances it out [19].

\section{Topic Modeling (Latent Dirichlet Allocation Algorithm)}

LDA (Latent Dirichlet Allocation) is a probabilistic generative model of a corpus. The core premise is that documents are represented as random mixtures of latent subjects, each of which is defined by a word distribution [21].

For each document $w$ in a corpus D, LDA assumes the following generative process:

$$
\begin{aligned}
& \text { Choose } \mathrm{N} \sim \operatorname{Poisson}(\xi) \\
& \text { Choose } \theta \sim \operatorname{Dir}(\alpha)
\end{aligned}
$$

For each of the $\mathrm{N}$ words wn

(a) Choose a topic $\mathrm{zn} \sim \operatorname{Multinomial}(\theta)$

(b) Choose a word wn from $\mathrm{p}(\mathrm{wn} \mid \mathrm{zn}, \beta)$, a multinomial probability conditioned on the topic $\mathrm{zn}$.

LDA is used to analyze the texts for patterns, themes, and structures, as well as how these themes were interrelated. It efficiently classifies vast amounts of data into categories based on patterns and attributes. In social science research, topic modeling has been frequently employed to achieve a descriptive understanding of unstructured texts [22]. A study in 2015 evaluated various topic modelling techniques and determined LDA as an effective technique in modelling topics with a document [23]. Similarly, Kherwa and Bansal observed that LDA is an effective topic modeling technique that can be used for classification, feature selection, and information retrieval [24].

\section{VADER Sentiment Analysis}

VADER (Valence Aware Dictionary for Sentiment Reasoning) is a sentiment analysis model used to determine the polarity (positive/negative) and intensity (strength) of the emotion of a corpus or set of documents. In 2014 the VADER model was introduced. It uses human-centric methodology that combines qualitative analysis and empirical validation utilizing human evaluators and crowdsourcing. To quantify the emotion of a word, VADER relies on a dictionary which maps words to emotion intensities called sentiment scores. The score of a text is computed by summing up the intensity value of each word in a corpus of documents. The scale used in measuring the emotion intensity ranges from -4 to +4 , where -4 is the largest negative score (most negative) and +4 as the most positive. Meanwhile, 0 (midpoint) is considered neutral. A normalization formula is applied to the overall emotion intensity to map the score within a range of -1 to +1 [25], [26]. In a study at the Georgia Institute of Technology, VADER along with other very common and highly regarded sentiment analysis tools were compared and were evaluated based on their ability to classify emotions, it was observed that VADER performed well and mostly better than the rest of the sentiment analysis tools [25]. The same results were also obtained by Al-Shabi [27]. This is the main reason why VADER was utilized in the study.

\section{E. Interpretation and Exhaustive Discussion}

In interpreting the results, the researchers described the findings in details followed by an exhaustive discussion about the phenomenon that revealed and was supported by the literature. The discussion aimed to answer the gaps stated in the introduction. Depth articulation of the findings by answering how did it happen, why did it happen, and what should be done is just some idea in presenting the analysis in the discussion part.

\section{F. Research Framework}

Fig. 1 shows the flow of data in Orange Data Mining [28] from raw data which were loaded using the Import Documents widget. The raw data were then preprocessed and cleaned using the Preprocess Text widget. After preprocessing, the Topic Modelling, Sentiment Analysis, Multidimensional Scaling, and Word Cloud were generated.

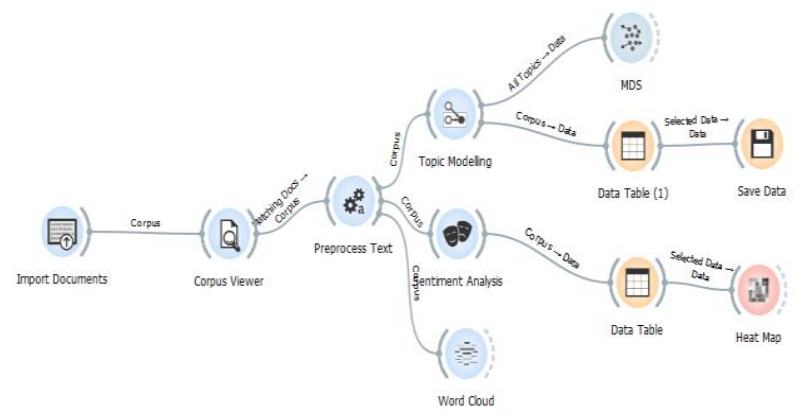

Fig. 1. Research framework.

\section{G. Programming and Online Tool Used in the Study}

This study utilized the Orange Data Mining Software to do the text processing, topic modelling, sentiment analysis and word cloud generation. Orange is an open-source machine learning and data visualization software. It builds data analysis workflows visually, with a large, diverse toolbox [28].

\section{H. Ethical Consideration and Reflexivity}

Conducting research specifically research that involves responses from individuals must always follow ethical standards. The names of the faculty members were transformed to code (part1, part2, part3, ...) before preprocessing of documents, and only the contents of the documents/responses will be utilized in this study. The sole intention of the researchers in conducting this research is only to reveal underlying sentiments and themes of faculty members towards the shift from conventional to online teaching.

\section{RESULTS AND DisCUSSION}

\section{A. Word Cloud}

A word cloud was generated to determine the frequently occurring words in the responses of teachers. Visualization of 
the data obtained is clearer with the use of a Word Cloud. It shows the tokens in the corpus, with the size of the words indicating their frequency. The prevalent words in the collection of responses were blended, online, students, teaching, teachers, learning, difficult, challenging, internet, and connectivity (See Fig. 2).

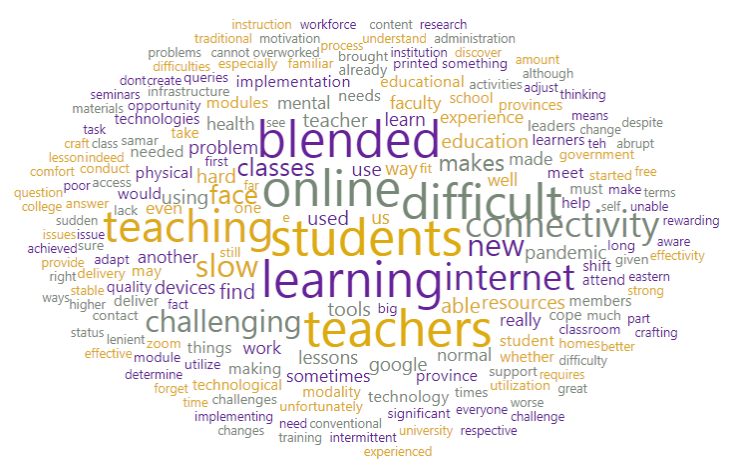

Fig. 2. Word cloud.

\section{B. Sentiment Analysis Result}

After applying the VADER sentiment analysis model, results revealed that $62 \%$ or 23 out of the 37 responses had a compound sentiment of negative. These teachers were identified to be part1, part2, part3, part4, part5, part6, part 6, part8, part12, part13, part14, part15, part16, part21, part22, part23, part24, part29, part30, part31, part33, part35, part36, part37 (See Table I). This result can be corroborated with prevalent words shown in Fig. 3 such as difficult, challenging and slow. The negative sentiments can be caused by a number of reasons. Talidong \& Toquero (2020) said that sudden changes in the working environment, closure of schools and isolation, teachers may experience sudden anxiety [29]. Amadora (2020) mentioned the difficulties and challenges faced by both teachers and students in the conduct of online classes. She mentioned that poor internet connectivity, outdated devices and software, system glitches and the very short attention span of students are the primary issues that arise in the conduct of online classes [30]. The negative sentiment can be visualized further using a heatmap shown in Fig. 3. It highlights the color blue which means that most of the teachers were leaning towards a negative sentiment.

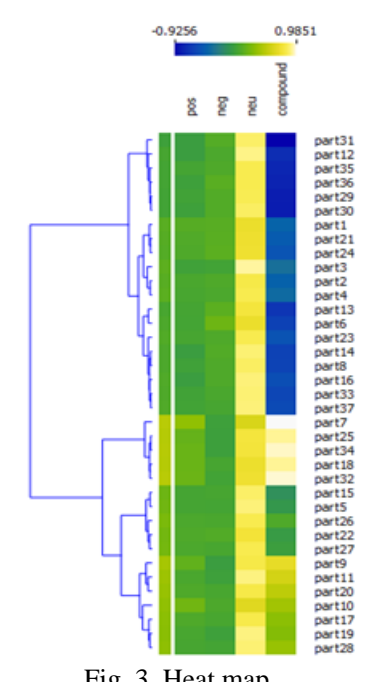

Fig. 3. Heat map.

TABLE I: SENTIMENT ANALYSIS RESULT

\begin{tabular}{|c|c|c|c|c|c|c|c|c|c|}
\hline Participant & pos & neg & neu & compound & Participant & pos & neg & neu & compound \\
\hline part1 & 0.134 & 0.144 & 0.722 & -0.415 & part20 & 0.106 & 0.074 & 0.82 & 0.5065 \\
\hline part2 & 0.082 & 0.103 & 0.815 & -0.4176 & part21 & 0.112 & 0.153 & 0.735 & -0.4588 \\
\hline part3 & 0.027 & 0.042 & 0.931 & -0.3291 & part22 & 0.105 & 0.12 & 0.775 & -0.0258 \\
\hline part4 & 0.074 & 0.093 & 0.833 & -0.3685 & part23 & 0.064 & 0.108 & 0.828 & -0.5106 \\
\hline part5 & 0.061 & 0.05 & 0.889 & -0.0516 & part24 & 0.104 & 0.157 & 0.738 & -0.5046 \\
\hline part6 & 0.055 & 0.228 & 0.717 & -0.6249 & part25 & 0.198 & 0.017 & 0.785 & 0.9217 \\
\hline part7 & 0.355 & 0.025 & 0.62 & 0.9851 & part26 & 0.088 & 0.084 & 0.828 & 0.1027 \\
\hline part8 & 0.031 & 0.104 & 0.864 & -0.6096 & part27 & 0.092 & 0.076 & 0.832 & 0.0102 \\
\hline part9 & 0.182 & 0 & 0.818 & 0.7003 & part28 & 0.069 & 0.049 & 0.882 & 0.3731 \\
\hline part10 & 0.243 & 0.099 & 0.658 & 0.4118 & part29 & 0.036 & 0.123 & 0.84 & -0.8248 \\
\hline part11 & 0.081 & 0.023 & 0.896 & 0.5994 & part30 & 0.019 & 0.123 & 0.858 & -0.8354 \\
\hline part12 & 0 & 0.09 & 0.91 & -0.7447 & part31 & 0 & 0.129 & 0.871 & -0.9256 \\
\hline part13 & 0.061 & 0.155 & 0.784 & -0.7003 & part32 & 0.215 & 0.042 & 0.744 & 0.967 \\
\hline part14 & 0 & 0.116 & 0.884 & -0.6124 & part33 & 0.038 & 0.08 & 0.883 & -0.5927 \\
\hline part15 & 0.063 & 0.069 & 0.868 & -0.1045 & part34 & 0.206 & 0.017 & 0.777 & 0.956 \\
\hline part16 & 0 & 0.106 & 0.894 & -0.5402 & part35 & 0.063 & 0.103 & 0.834 & -0.7816 \\
\hline part17 & 0.107 & 0.072 & 0.821 & 0.34 & part36 & 0.025 & 0.146 & 0.829 & -0.7918 \\
\hline part18 & 0.208 & 0.065 & 0.727 & 0.9179 & part37 & 0.048 & 0.064 & 0.888 & -0.5647 \\
\hline part19 & 0.071 & 0.026 & 0.902 & 0.3104 & & & & & \\
\hline
\end{tabular}

\section{Topic Modelling Result}

The responses were fed to a topic modelling widget and created five (5) topics. It can be observed in Table II that 26 out of the 37 responses or 70 percent of the participants were mainly talking about topic 5. The keywords included in topic 5 as shown in Table III were student, online, teaching, slow, learning, blended, internet, classes, connectivity and way. The researchers tagged the keywords with the theme "Slow Internet Connectivity as a Major Impediment in the Conduct 
of Online Teaching”. The research of Rotas and Cahapay (2020) indicated unstable internet connectivity as one of key challenges they face when doing flexible learning specifically online learning [31]. Slow internet connections has a significant impact on teachers' online synchronous classes. It either causes problems with the web platform or causes audio issues. Even if some teachers are completely competent of giving online classes, a large number of students are still unable to access the internet in order to complete their additional research [32].

Additional analysis can be drawn with the Multidimensional Scaling (MDS) which shows how each topic dominance and how they are is related to each other (see Fig. 4). It can be observed in Fig. 3 that topic 5 is the largest in size which means that is has the highest topic probability. It can also be observed that topics 1,2,3 are closer to each other which means that the themes of their topics are highly related to each other.

TABLE II: TOPIC PROBABILITY OF TEACHER'S RESPONSES

\begin{tabular}{|c|c|c|c|c|c|c|c|c|c|c|c|}
\hline Participant & \begin{tabular}{|l|} 
Topic 1 \\
\end{tabular} & Topic 2 & \begin{tabular}{|l|} 
Topic 3 \\
\end{tabular} & \begin{tabular}{|l|} 
Topic 4 \\
\end{tabular} & \begin{tabular}{|l|} 
Topic 5 \\
\end{tabular} & Participant & \begin{tabular}{|l|} 
Topic 1 \\
\end{tabular} & Topic 2 & \begin{tabular}{|l|} 
Topic 3 \\
\end{tabular} & Topic 4 & \begin{tabular}{|l|} 
Topic 5 \\
\end{tabular} \\
\hline part1 & 0 & 0.213765 & 0 & 0 & 0.767998 & part20 & 0 & 0.243525 & 0 & 0 & 0.742963 \\
\hline part2 & 0.12178 & 0.01898 & 0.163761 & 0 & 0.692343 & part21 & 0.235152 & 0 & 0 & 0 & 0.74573 \\
\hline part4 & 0 & 0.14865 & 0 & 0 & 0.842906 & part23 & 0 & 0 & 0 & 0.531149 & 0.454363 \\
\hline part5 & 0 & 0 & 0 & 0 & 0.975489 & part24 & 0 & 0 & 0.549385 & 0 & 0.437966 \\
\hline part6 & 0.013336 & 0.013335 & 0.01335 & 0.473466 & 0.486513 & part25 & 0.42781 & 0 & 0 & 0 & 0.558697 \\
\hline part7 & 0 & 0.374905 & 0.332218 & 0 & 0.280075 & part26 & 0 & 0.476909 & 0 & 0 & 0.509077 \\
\hline part8 & 0.513035 & 0 & 0 & 0 & 0.466179 & part27 & 0 & 0 & 0 & 0.529291 & 0.459942 \\
\hline part9 & 0.014293 & 0.014302 & 0.337239 & 0.619434 & 0.014731 & part28 & 0 & 0 & 0.212035 & 0 & 0.778257 \\
\hline part10 & 0.02944 & 0.029316 & 0.029617 & 0.029346 & 0.882281 & part29 & 0 & 0 & 0.445021 & 0 & 0.540663 \\
\hline part11 & 0.353221 & 0.173294 & 0.248989 & 0 & 0.220345 & part30 & 0 & 0 & 0 & 0 & 0.984224 \\
\hline part12 & 0.041214 & 0.180658 & 0 & 0.124062 & 0.648535 & part31 & 0 & 0.171585 & 0 & 0.259363 & 0.561198 \\
\hline part14 & 0 & 0 & 0 & 0.177217 & 0.795087 & part33 & 0 & 0.696202 & 0 & 0 & 0.288404 \\
\hline part15 & 0 & 0 & 0 & 0 & 0.979466 & part34 & 0 & 0.30637 & 0.534668 & 0 & 0.151075 \\
\hline part16 & 0 & 0 & 0 & 0 & 0.963167 & part35 & 0 & 0.08855 & 0 & 0.37702 & 0.52794 \\
\hline part17 & 0 & 0 & 0 & 0 & 0.97828 & part36 & 0 & 0 & 0.217948 & 0 & 0.762033 \\
\hline part18 & 0 & 0.160231 & 0.015694 & 0.246483 & 0.572859 & part37 & 0.422078 & 0.035634 & 0 & 0.026339 & 0.513208 \\
\hline part19 & 0 & 0 & 0 & 0.592893 & 0.390528 & & & & & & \\
\hline
\end{tabular}

TABLE III: KEYWORDS GENERATED FROM TOPIC MODELING

\begin{tabular}{|c|c|c|c|c|c|c|c|c|c|c|c|}
\hline Topic & \multicolumn{10}{|c|}{ Topic Keywords } & \multirow{2}{*}{\begin{tabular}{|l|}
\multicolumn{1}{|c}{ Themes } \\
$\begin{array}{l}\text { Unexpected shift from conventional to } \\
\text { blended teaching }\end{array}$ \\
\end{tabular}} \\
\hline Topic 1 & changes & part & terms & shift & revealed & $\begin{array}{l}\text { pedagogie } \\
\text { s }\end{array}$ & unexpected & gaps & sudden & adopt & \\
\hline Topic 2 & pandemic & using & health & some & physical & nental & stress & take & despite & would & $\begin{array}{l}\text { Mental and Physical Health issues } \\
\text { related to the implementation of Blended } \\
\text { Learning }\end{array}$ \\
\hline Topic 3 & good & fit & google & presented & modalities & different & zoom & way & instruction & meet & $\begin{array}{l}\text { Online tools used in the conduct of } \\
\text { Online Classes }\end{array}$ \\
\hline Topic 4 & lessons & deliver & difficult & activities & experience & may & $\begin{array}{l}\text { challengin } \\
\mathrm{g}\end{array}$ & varied & modalities & presented & $\begin{array}{l}\text { Difficulties and Challenges in the } \\
\text { conduct of Blended Teaching and } \\
\text { Learning }\end{array}$ \\
\hline Topic 5 & students & online & teaching & slow & learning & blended & internet & classes & connectivity & way & $\begin{array}{l}\text { Slow Internet connectivity as a major } \\
\text { Impedement in the conduct of Online } \\
\text { Teaching }\end{array}$ \\
\hline
\end{tabular}

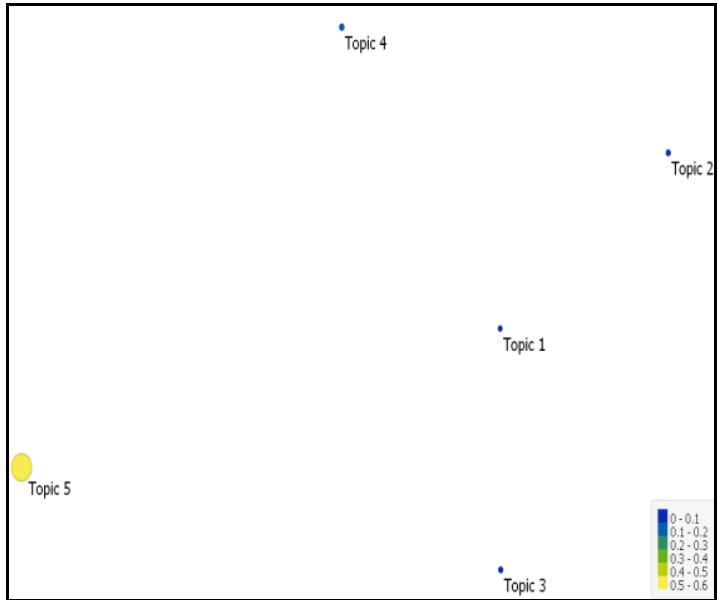

Fig. 4. Multidimensional scaling.

\section{Themes Generated from the Topic Keywords using $L D A$}

Using the Latent Dirichlet Allocation Topic Modelling technique, five (5) Major topics were generated with ten (10) keywords per topic. The keywords were then analyzed to generate their underlying latent themes as was done by Caluza (2018) [33]. The following themes were generated.

Theme 1: Unexpected shift from conventional to blended teaching

The COVID19 pandemic has severely affected the entire globe. More than 176 million individuals have been infected and over three million have died as of June of 2021. This amounts to over 1.3 million sick people and 22,788 deaths in 
the Philippines [34]. Most countries have chosen to use quarantine protocols and temporarily close their educational institutions in order to stop COVID-19 from spreading. As a result, over a billion students and millions of teachers around the world have been impacted [10]. To meet the demands of students, particularly the more than three million tertiary students enrolled in nearly 2,400 HEIs across the country, the Commission on Higher Education (CHED) released CMO 04, s. of 2020, otherwise known as the "Guidelines on the Implementation of Flexible Learning". The memorandum urges HEIs to explore various innovative methodologies, strategies and modalities that will facilitate the shift from conventional to blended or flexible learning [4]. Certain HEIs have established proactive strategies to ensure that education continues despite its closure. Modified types of online learning are included in these policies, with the goal of facilitating student learning activities [10]. But despite these, many educators are hesitant with the use of blended or online learning as a primary methodology of teaching. Furthermore, there is also the country's long-standing problem with bad internet connectivity which both represent obstacles to the adoption of online education in the Philippines [35]. Transition during change is frequently accompanied by feelings of hesitation and resistance, according to Kurt Lewin's 3 Stage Change Model [36]. The feeling of hesitation maybe caused by the fear of using a totally different type of teaching methodology, although faculty indifference and resistance to technology integration is not uncommon [37]. According to studies, there is a disconnect between administrators' and faculty's perspectives on the use of online education. Issues affecting student performance, such as effective communication, technical skill, and accomplishment of learning outcomes without cheating, were of special interest to instructors. Faculty were also concerned about their own standing as online lecturers within the institution's greater culture [38].

Participant 2: "The abrupt shifting from the conventional form of teaching to online teaching has brought forth numerous difficulties on both the teacher and learners' end"

Participant 6: "It caught me off guard. Lack of technology and poor internet connection made this online/blended learning a challenge in delivering lessons"

Participant 13: "For me, it is hard to suddenly shift from conventional to blended or online teaching, because ifor one is not familiar with online tools to be used for blended teaching"

Theme 2: Mental and Physical Health Issues Related to the Implementation of Blended Learning

The Philippines has been one of Asia's hardest-hit countries due to the coronavirus's long-term and broad spread. As of this writing, the Philippines has the second-highest number of COVID-19 cases in Southeast Asia [39]. With the sudden changes in the working environment, closure of schools and isolation, teachers may experience sudden anxiety [29], [7]. Apart from the obvious physical health risks, COVID-19's psychological impact poses major threats and dangers to mental health and well-being, as heightened levels of anxiety and stress are worsened by the situation's ongoing uncertainty. Aside from the possible stressors teachers encounter as a result of the COVID-19 threat, they are also required to adjust to the new normal in the educational landscape and engage in effective remedial education [7], [40], [35]. Teachers may not have the technologies, resources, or skills necessary to engage in and succeed in this new mode of instruction. In generalization, many people's lives were changed as a result of COVID-19. It instilled fear, trauma, depression, and anxiety in people, particularly those who had lost loved ones as a result of the pandemic. Filipinos, especially teachers, are concerned about the safety of their loved ones, and their lifestyles have been impacted as a result of the pandemic's fears. Though the Filipino teachers have maintained an optimistic attitude in the face of the COVID-19 epidemic, they are nonetheless vulnerable to fears as the epidemic continues to spread over the world. These teachers, on the other hand, are fully aware of how to deal with their educational, social, and personal concerns [29].

\section{Participant 33: "I am more concerned with the mental and physical health of faculty members. Because of so many deadlines to be met, teachers are sometimes over-drowned with work that they don't have any breather." \\ Participant 37: "Same goes for us teachers not all have the access and resources and some even do not know how to navigate these gadgets which requires us to exert more work and effort in order to provide quality education for the students. Not to mention the trauma, mental health issues and problems it gives to students and teachers"}

\section{Theme 3: Online tools used in the conduct of Online Classes}

Online education has evolved as a cutting-edge teaching and learning tool throughout the last decade. This strategy is used by learners of all ages, from working individuals who wish to continue their education while on the job to parents who enroll their children to help them learn new things to students who are unable to unable to continue their studies owing to medical issues or impairments are in the same boat. Such students can now continue their education through a variety of distant learning programs [41]. The need to use online teaching and learning tools has been more highlighted with the spread of COVID-19 [42]. Online learning can include synchronous, real-time lectures and time-based outcomes evaluations, as well as asynchronous, delayed time activities such as pre-recorded video lectures and time-independent evaluations [43]. Many online learning platforms and tools have been introduced to help sustain education. Online platforms such as google, tv broadcasts, learning management systems, online channels and video resources have been utilized by many HEIs [44], [45]. In online learning, majority of the activities are done online while communication and interaction are done using virtual classrooms, online education boards, and videoconferencing 
[46]. The study of Reyes-Chua et al. (2020) revealed that most educators in the higher education use Google Classroom, Edmodo, Zoom, FB Messenger, Google meet, We Chat, Schoology, and Moodle as their primary online teaching tools [47].

Participant 19: "Using google meet is very simple but many of my students were not able to attend class because of the very slow internet connectivity."

Participant 31: "I was able to learn new technologies such as YouTube video making, google meet, google classroom and zoom."

Theme 4: Difficulties and Challenges in the Conduct of Blended/Online Learning

The sudden move of governments to do community lockdowns and wide-spread quarantine has forced educational leaders to let students and teachers' study and work from home using flexible learning modalities [48], [44]. However, the introduction of flexible learning especially online learning presented a variety of issues and concerns to both professors and students, particularly in higher education institutions (HEIs) [3]. Many instructors who prefer in-person instruction have found the rapid shift to flexible learning to be extremely stressful [49]. Online learning is sometimes portrayed as a less desirable choice that gives a lower-quality education than face-to-face instruction [50]. There are numerous strategies and technologies available for flexible learning, however they can sometimes cause significant problems. The crafting and delivery of self-learning modules (SLMs) take so much time [51], while use online learning tools may cause downloading faults, installation issues, login issues, audio and visual problems, and so on [52]. Dhawan (2020) explained further that student may find online instruction to be tedious and uninteresting at times. Online teaching and learning offer very flexible time to both teachers and students that they have a hard time doing it [52]. Keeton (2004) explained that educators must devote a significant amount of work to developing efficient online instruction methodologies [53]. Effective online instructions encourage learners to provide feedback, ask questions, and deepen their understanding of the course material. However, Reyes-Chua et al., (2020) argue that one of the key issues in the implementation of online learning platforms is the lack of training of faculty members [47]. In the article of Amadora (2020), she clearly mentioned the difficulties and challenges faced by both teachers and students in the conduct of online classes. She mentioned that poor internet connectivity, outdated devices and software, system glitches and the very short attention span of students are the primary issues that arise in the conduct of online classes [30]. Indeed, online learning has its plethora of advantages but this should not hinder both teachers and students from being aware and sensitive of the various situations each one is facing.

Participant 2: "The abrupt shifting from the conventional form of teaching to online teaching has brought forth numerous difficulties on both the teacher and learners' end. The fact that some teachers are not

\section{adept to online teaching cannot be denied, this makes} our work very difficult",

Participant 16: "Blended learning is really difficult to implement in this new normal. Not all students have devices to use for online learning. For me, modules both e-copy and printed are very hard to prepare"

Theme 5: Slow Internet Connectivity as a Major Impediment in the Conduct of Online Teaching

According to an Akamai (2017) analysis, the Philippines has Asia's worst internet connectivity [13]. This evident with the very slow to no internet connectivity of the low-income sector and people in rural areas [25]. The problem with internet connectivity has already been plaguing the Philippines even before the onslaught of the pandemic [5]. Participants of the study of Rotas and Cahapay (2020) indicated unstable internet connectivity as one of key challenges they face when doing flexible learning specifically online learning [31]. Poor network is a typical issue for developing countries with inadequate telecommunications and information and communication technology (ICT) [54]. The slow internet connectivity greatly affects the online synchronous classes being done by teachers. It either cause glitches with the online platform or it results to audio problems. And even if some teachers are fully capable of conducting online classes, a huge number of students are still unable to connect to the internet to do their supplemental research work. Twenty percent of the 65 million students who has internet access use public computer shops and free public internet to connect online and a staggering 2.8 million students have no way of accessing the internet at all [32].

Participant 5: "One big problem is the slow internet connectivity to both students and teachers. Because the teachers sometimes have to deliver their classes online, they have to have stable internet connectivity."

Participant 17: "The implementation of e-learning or blended learning is a learning opportunity for us teachers, although there are constraints such as slow internet connectivity and lack of devices to be used for blended learning which makes teaching challenging and difficult"

\section{CONCLUSION}

This study aimed at determining the sentiment and the underlying themes in the responses of faculty members towards the shift from conventional to online learning using data mining techniques. Results revealed that the most frequently occurring words in the responses of teachers were blended, online, students, teaching, teachers, learning, difficult, challenging, internet, and connectivity. Twenty-three (23) out of $37(62 \%)$ responses were determined to have negative polarity making the general sentiment of faculty members towards the shift to online learning negative. The following themes were generated after the application of Latent Dirichlet Allocation Topic 
Modeling technique: unexpected shift from conventional to blended teaching, Mental and Physical Health Issues Related to the Implementation of Blended Learning, Online tools used in the conduct of Online Classes, Difficulties and Challenges in the Conduct of Blended/Online Learning, Slow Internet Connectivity as a Major Impediment in the Conduct of Online Teaching. These themes implies that many teachers are encountering problems with the use of blended or online learning. Teachers were not mentally and technologically prepared to use online tools for teaching. This situation was worsened with the country's very slow internet connectivity. The results of this research shows that problems indeed occurred and is still occurring in the shift from the conventional way of teaching into blended or online modality. The researcher highly recommends the following: 1) conduct of quarterly mental health check of its students and faculty members to ensure that everyone is mentally and physically prepared to attend online classes especially during this time of pandemic, 2) conduct a massive upgrading of infrastructure, equipment and devices that will aide both teacher and students in the conduct of online and blended classes. 3) A massive skill upgrading of tools and devices for online teaching and learning must be carried out to ensure that educators are equipped with the necessary skills to conduct online/blended classes and 4) tie-up with internet service providers, DICT, and the LGU to ensure that a strong internet infrastructure within the locality is established.

\section{CONFLICT OF INTEREST}

The author declares no conflict of interest.

\section{AUTHOR CONTRIBUTIONS}

Niel Francis Casillano is the principal author of the study.

\section{REFERENCES}

[1] F. Reimers, A. Schleicher, J. Saavedra, and S. Tuominen, "Supporting the continuation of teaching and learning during the COVID-19 Pandemic," OECD, vol. 1, no. 1, pp. 1-38, 2020.

[2] M. A. Flores and M. Gago, "Teacher education in times of COVID-19 pandemic in Portugal: national, institutional and pedagogical responses," Journal of Education for Teaching, DOI: 10.1080/02607476.2020.1799709, 2020.

[3] W. Bao, "COVID-19 and online teaching in higher education: A case study of Peking University", Human Behavior and Emerging Technologies, 2020.

[4] CHED, CHED COVID-19 ADVISORY NO. 3. (2020). [Online]. Available:

https://ched.gov.ph/wp-content/uploads/CHED-COVID-2019-Adviso ry-No.-3.pdf

[5] N. F. B. Casillano, "Challenges of implementing an e-learning platform in an internet struggling province in the Philippines," Indian Journal of Science and Technology, vol. 12, no. 10, pp. 1-4, 2019.

[6] E. Yariv, "Deterioration in teachers' performance: Causes and some remedies" World Journal of Education, vol. 1, no. 1, pp. 81-91, 2011.

[7] J. Rabacal, R. M. Oducado, and K. Tamdang, "COVID-19 impact on the quality of life of teachers: A cross-sectional Study," Asian Journal for Public Opinion Research, vol. 8, no. 4, pp. 478-492, 2020.

[8] E. M. Bridges, The Incompetent Teacher: Managerial Response (rev.), London: The Falmer Press, 1992

[9] Worldometer. [Online]. Available: https://www.worldometers.info/coronavirus/country/philippines/

[10] J. J. B. Joaquin, H. T. Biana, and M. A. Dacela MA, "The Philippine higher education sector in the time of COVID-19," Front. Educ., vol. 5, p. 576371 .

[11] A. Abidah, H. N. Hidaayatullaah, R. M. Simamora, D. Fehabutar, and L. Mutakinati, "The impact of Covid-19 to Indonesian education and its relation to the philosophy of "MerdekaBelajar","SiPoSE: Studies in Philosophy of Science and Education, vol. 1, no. 1, pp. 38-49, 2020.

[12] A. Parrocha, HEIs May Hold Limited Face-to-face Classes in MGCQ Areas, Quezon City, PH: Philippine News Agency.

[13] Akamai, Akamai's State of the Internet, Akamai, vol. 10, no. 1, 2017.

[14] G. Basilaia and D. Kvavadze, "Transition to online education in schools during a SARS-CoV-2 Coronavirus (COVID-19) pandemic in Georgia," Pedagogical Research, vol. 5, no. 4, 2020.

[15] B. Saberi and S. Saad, "Sentiment analysis or opinion mining: A review," International Journal on Advanced Science Engineering and Information Technology, pp. 1660-1666, 2017.

[16] M. M. Altawaier and S. Tiun, "Comparison of machine learning approaches on arabic twitter sentiment analysis," International Journal on Advanced Science, Engineering and Information Technology, vol. 6, no. 6, pp. 1067-1073, 2016.

[17] K. Isoaho, D. Gritsenko, and E. Mäkelä, "Topic modeling and text analysis for qualitative policy research," Policy Studies Journal, vol. 49, no. 1, pp. 300-324, 2021

[18] Columbia Public Health. (n.d.). Content Analysis. [Online]. Available: https://www.publichealth.columbia.edu/research/population-health-m ethods/content-analysis

[19] S. Vijayarani, M. J. Ilamathi, and M. Nithya, "Preprocessing techniques for text mining-an overview," International Journal of Computer Science \& Communication Networks, vol. 5, no. 1, pp. 7-16, 2015.

[20] C. Ramasubramanian and R. Ramya, "Effective pre-processing activities in text mining using improved porter's stemming algorithm," International Journal of Advanced Research in Computer and Communication Engineering ,vol. 2, issue 12, December 2013.

[21] D. M. Blei A. Y. Ng, and M. I. Jordan, "Latent dirichlet allocation," Journal of Machine Learning Research, vol. 3, pp. 993-1022, 2003.

[22] J. Xue, J. Chen, R. Hu, C. Chen, C. Zheng, Y. Su, and T. Zhu, “Twitter discussions and emotions about the COVID-19 pandemic: Machine learning approach," Journal of medical Internet research, vol. 22, no. $11,2020$.

[23] E. Jónsson and J. Stolee, “An evaluation of topic modelling techniques for twitter," University of Toronto, 2015.

[24] P. Kherwa and P. Bansal, "Topic modeling: A comprehensive review," EAI Endorsed Transactions on Scalable Information Systems, vol. 7, no. $24,2020$.

[25] C. Hutto and E. Gilbert, "VADER: A parsimonious rule-based model for sentiment analysis of social media text," in Proc. the International AAAI Conference on Web and Social Media, vol. 8, no. 1, 2014.

[26] P. Calderon. (April 2017). Vader Sentiment Analysis Explained. [Online]. http://datameetsmedia.com/vader-sentiment-analysis-explained/

[27] M. A. Al-Shabi, "Evaluating the performance of the most important Lexicons used to Sentiment analysis and opinions Mining," IJCSNS, vol. 20, no. 1, 2020.

[28] J. Demsar, T. Curk, A. Erjavec, C. Gorup, T. Hocevar, M. Milutinovic, M. Mozina, M. Polajnar, M. Toplak, A. Staric, M. Stajdohar, L. Umek, L. Zagar, J. Zbontar, M. Zitnik, and B. Zupan, "orange: data mining toolbox in python," Journal of Machine Learning Research, vol. 14, pp. 2349-2353, 2013.

[29] K. J. B. Talidong and C. M. D. Toquero, "Philippine teachers' practices to deal with anxiety amid COVID-19," Journal of Loss and Trauma, vol. 25 , no. 6-7, pp. 573-579.

[30] M. G. Amadora. (September 2020). Common Problems that Occur During Online Classes. [Online]. Available: https://mb.com.ph/2020/09/18/common-problems-that-occur-during-o nline-classes/

[31] E. E. Rotas and M. B. Cahapay, "Difficulties in remote learning: Voices of Philippine university students in the wake of COVID-19 crisis," Asian Journal of Distance Education, vol. 15, no. 2, pp. 147-158, 2020.

[32] A. P. Santos. (October 2020). In the Philippines, distance learning reveals the digital divide. [Online]. Available: https://eu.boell.org/en/2020/10/06/philippines-distance-learning-revea ls-digital-divide

[33] L. J. B. Caluza, "Deciphering west Philippine sea: A Plutchik and VADER algorithm sentiment analysis," Indian Journal of Science and Technology, vol. 11, no. 47, 2018.

[34] Worldometer. (2021). Worldometer Philippines. [Online]. Available: https://www.worldometers.info/coronavirus/country/philippines/

[35] R. Moralista and R. M. Oducado, "Faculty perception toward online education in higher education during the coronavirus disease 19 (COVID-19) pandemic," SSRN, 2020. 
[36] D. Batras, C. Duff, and B. J. Smith, "Organizational change theory: Implications for health promotion practice," Health Promotion International, vol. 31, no. 1, pp. 231-41, 2016.

[37] P. B. Arinto, "Issues and challenges in open and distance e-learning: Perspectives from the Philippines," International Review of Research in Open and Distributed Learning, vol. 17, no. 2, pp. 162-180, 2016.

[38] N. P. Wingo, N. V. Ivankova, and J. A. Moss, "Faculty perceptions about teaching online: Exploring the literature using the technology acceptance model as an organizing framework," Online Learning, vol. 21, no. 1, pp. 15-35, 2017.

[39] Center for Strategic and International Studies. (2021). Southeast Asia Covid-19 Tracker. [Online]. Available: https://www.csis.org/programs/southeast-asia-program/projects/south east-asia-covid-19-tracker

[40] J. N. Guillasper, G. P. Soriano, and R. M. F. Oducado, "Psychometric properties of 'attitude towards e-learning scale' among nursing students," International Journal of Educational Sciences, vol. 30, no. $1-3,2020$.

[41] J. Obana. (2020). What will schools look like under the "new normal". [Online].

Available: https://www.manilatimes.net/2020/05/13/business/columnists-busines s/what-will-schools-look-like-under-the-new-normal/724556

[42] R. E. Baticulon, J. J. Sy, N. R. I. Alberto et al., "Barriers to online learning in the time of COVID-19: A national survey of medical students in the Philippines," Medical Science Educator, vol. 31, no. 2 , pp. 615-626, 2021

[43] M. Oztok, D. Zingaro, C. Brett, and J. Hewitt, "Exploring asynchronous and synchronous tool use in online courses," Comput. Educ., vol. 60, pp. 87-94, 2013.

[44] J. Z. Tria, "The COVID-19 pandemic through the lens of education in the Philippines: The new normal," International Journal of Pedagogical Development and Lifelong Learning, vol. 1, no. 1, pp. 2-4, 2020.

[45] UNESCO. (2020). COVID-19 Educational Disruption and Response. [Online]. Available: https://en.unesco.org/covid19/educationresponse

[46] C. J. B. Landicho, "Changes, challenges, and opportunities in teaching senior high school earth science amidst the COVID-19 pandemic," Journal of Learning and Teaching in Digital Age, vol. 6, no. 1, pp. 55-57, 2021.

[47] E. Reyes-Chua, B. G. Sibbaluca, R. D. Miranda, G. B. Palmario, R. P Moreno, and J. P. T. Solon, "The status of the implementation of the e-learning classroom in selected higher education institutions in region
IV-A amidst the covid-19 crisis," Journal of Critical Reviews, vol. 7 , no. 11, pp. 253-258, 2020.

[48] J. Crawford, K. Butler-Henderson, R. Jurgen, B. H. Malkawi, M. Glowatz, R. Burton, P. Magni, and S. Lam, "COVID-19: 20 countries' higher education intra-period digital pedagogy responses," Journal of Applied Learning \& Teaching, 2020.

[49] K. F. Hew, C. Jia, D. E. Gonda, and S. Bai. "Transitioning to the "new normal" of learning in unpredictable times: pedagogical practices and learning performance in fully online flipped classrooms," International Journal of Educational Technology in Higher Education, vol. 17, no. 1, pp. 1-22, 2020

[50] C. Hodges, S. Moore, B. Lockee, T. Trust, and A. Bond. "The difference between emergency remote teaching and online learning," Educause Review, 2020.

[51] M. Hernando-Malipot, "Teachers air problems on modular learning system," August 2020.

[52] S. Dhawan, "Online learning: A panacea in the time of COVID-19 crisis," Journal of Educational Technology Systems, vol. 49, no. 1, pp. $5-22,2020$.

[53] M. T. Keeton, "Best online instructional practices: Report of phase I of an ongoing study," Journal of Asynchronous Learning Networks, vol. 8, no. 2, pp. 75-100, 2004

[54] E. Aboagye, J. A. Yawson, and K. N. Appiah, "COVID-19 and E-learning the challenges of Students in tertiary institutions in Ghana," Social Education Research, 2020.

Copyright $\odot 2022$ by the authors. This is an open access article distributed under the Creative Commons Attribution License which permits unrestricted use, distribution, and reproduction in any medium, provided the original work is properly cited (CC BY 4.0).

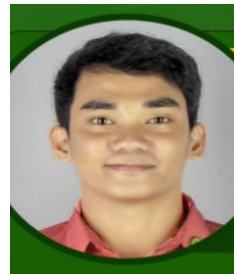

Niel Francis Casillano earned his BSc in information technology at Leyte Normal University, Philippines. He obtained his masters in teaching Computer science at Southwestern University, Philippines. $\mathrm{He}$ is presently affiliated with Eastern Samar State University as an instructor. His research interests are in the field of software development, data mining, NLP and software quality. 